\title{
Prediction of miscarriage in first trimester by serum estradiol, progesterone and $\beta$-human chorionic gonadotropin within 9 weeks of gestation
}

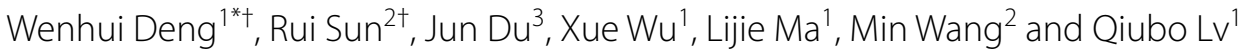

\begin{abstract}
Purpose: To predict miscarriage outcome within 12 weeks of gestational age by evaluating values of serum estradiol, progesterone and $\beta$-human chorionic gonadotropin ( $\beta-H C G$ ) within 9 weeks of gestation.

Methods: One hundred sixty-five women with singleton pregnancies were retrospectively studied. Estradiol, progesterone and $\beta$-HCG levels were measured at 5-6 weeks of gestation and the measurements were repeated at 7-9 weeks. According to pregnancy outcome at 12 weeks of gestation, 71 cases were categorized into miscarriage group, and 94 cases into group of normal pregnancy. Each group was further divided into 5-6 and 7-9 weeks of gestation sub-group. Predictive values of estradiol, progesterone and $\beta$ - HCG levels at 5-6 weeks and 7-9 weeks of gestation were analyzed with receiver operating characteristic (ROC) curves and logistic regression.

Results: Serum levels of estradiol at 7-9 weeks identified miscarriage with an area under the ROC curve (AUC) of $0.866(95 \% \mathrm{Cl} 0.793 \sim 0.938, P=0.000)$, diagnostic cutoff value of $576 \mathrm{pg} / \mathrm{ml}$, sensitivity of 0.804 , and specificity of 0.829 respectively at the optimal threshold, according to Youden index. Progesterone levels at $7-9$ weeks were with AUC of $0.766(95 \% \mathrm{Cl} 0.672 \sim 0.861, P=0.000)$, cutoff value of $15.27 \mathrm{ng} / \mathrm{ml}$, sensitivity of 0.921 , and specificity of 0.558 , respectively; Estradiol at 5-6 weeks were with AUC of 0.709 ( $95 \% \mathrm{Cl} 0.616 \sim 0.801, P<0.001)$, the diagnostic cutoff value of $320 \mathrm{pg} / \mathrm{ml}$, sensitivity of 0.800 , and specificity of 0.574 , respectively.

The performance of the dual markers of estradiol and progesterone analysis (AUC 0.871, Cl 0.793-0.950), three-markers analysis (AUC $0.869, \mathrm{Cl} 0.759-0.980$ ) were slightly better than the single marker at 7-9 weeks. $\beta$-HCG or progesterone provide additional utility of estradiol prediction at 5-6 weeks with AUC $0.770(0.672-0.869)$ for $\beta$-HCG and estradiol, AUC0.768(Cl 0.670-0.866) for $\beta-H C G$, estradiol and progesterone and AUC 0.739 ( $\mathrm{Cl} 0.651-0.827)$ for progesterone and estradiol.
\end{abstract}

Conclusions: Low serum levels such as dual of estradiol and progesterone or estradiol alone at 7-9 weeks, $\beta$-HCG or progesterone combing estradiol at 5-6 weeks of gestation can be used better to predict miscarriage in first trimester.

Keywords: Pregnancy, Estradiol, Progesterone, $\beta-H C G$, Miscarriage

*Correspondence: dengwenhui@hotmail.com

${ }^{\dagger}$ Wenhui Deng and Rui Sun contributed equally to this work.

1 Department of Obstetrics and Gynecology, Beijing Hospital, National

Center of Gerontology; Institute of Geriatric Medicine, Chinese Academy

of Medical Sciences, Beijing 100730, P. R. China

Full list of author information is available at the end of the article

\section{Introduction}

Pregnancy loss occurs in approximately $15-25 \%$ of pregnancies [1]. It is still the most common pregnancy complication affecting women's physical and mental health. Repeated Clinical examinations and treatments for 
threatened abortion also leads to economic and mental burdens on patients. But there is no reliable clinical indicator to predict it early yet. Low values and low growth rates of estradiol and $\beta$-human chorionic gonadotropin $(\beta$-HCG) probably indicate bad pregnancy outcome [2].

HCG - one of the most important endocrine factors as we known, can inhibit $\mathrm{T}$ cell stimulation and avoid variant stimulation of $\mathrm{T}$ lymphocyte reaction of embryo damage [3]. Initial HCG, HCG ratio [4], and too low rising speed of HCG at early pregnancy may indicate miscarriage or ectopic pregnancy [2]. Recent researches suggested that serum progesterone $[5,6]$, estradiol [2] and ultrasound [7, 8] can identify women with miscarriage. Whereas one study suggest that the most commonly used biomarkers of serum HCG and progesterone are not useful in predicting outcome of a pregnancy with a viable fetus [9]. The factors that predict pregnancy losses are not well understood [8]. Although both ultrasound and serial HCG values can, to some extent in the clinic, identify women at risk of miscarriage, study remains sparse on other more effective biomarkers, to identify at-risk pregnancies, especially before the onset of clinical symptoms [10].

Estrogen stimulating endometrial hyperplasia and myometrium thickness, increases blood supply and enhances uterine contraction force. Studies suggest that estradiol be an important factor to maintain early pregnancy $[11,12]$. In the 4 to 8 weeks of pregnancy, serum estradiol level was positively correlated with gestational age. Estradiol level at early pregnancy can reflect the quality of the dominant follicle and the function of corpus luteum as well as help maintain corpus luteum $[13,14]$. Serum estradiol were significantly lower in pregnant women with abortion than in those with normal pregnancy [13]. Estradiol and immune cells in pregnant women can work together to maintain normal pregnancy [12]. Estradiol has not been used as widely as $\beta$-HCG and $\mathrm{P}$, and its value in predicting pregnancy outcome is unclear [2].

Since endocrine factors, such as HCG, progesterone and estrogen, are critical for normal pregnancy, low levels of them may be markers of miscarriage. Retrospective analysis was carried out on the data of pregnant women diagnosed and followed at Obstetrics and Gynecology Clinic of Beijing Hospital from July 2015 to July 2016 and predicted miscarriage within the 12 weeks of gestation with receiver operating characteristic (ROC) curve of serum estradiol, progesterone and $\beta$-HCG at 5-9 weeks of gestation.

\section{Methods}

\section{Study population}

One hundred sixty-five women with singleton pregnancies were retrospectively studied. The healthy women aged between 21 and 40, with 5 weeks of singleton pregnancy were diagnosed at first visit by ultrasound screening (Ultrasonic apparatus GE V730). Their data was analyzed from July 2015 to July 2016 at Obstetrics and Gynecology Clinic of Beijing Hospital. Patients with recurrent miscarriage history, thyroid autoimmunity were excluded from the study. Pregnancies achieved by artificial assisted pregnancy technology (ART) such as intracytoplasmic injection (ICSI) or intrauterine insemination (IUI) was excluded also. The pregnancy was the first to the third time of women and there was no chromosomal abnormality history with previous fetus. Serum estradiol, progesterone and $\beta$-HCG levels of these women were measured twice at 5-6weeks and 7-9weeks of gestational age respectively. The research flow chart is shown in Fig. 1.

\section{Study design and setting}

Seventy-one cases diagnosed as miscarriage within 12 weeks of pregnancy were categorized into miscarriage group and the other 94 cases at 12 weeks were into normal pregnancy group (Table 1). Each group was further divided into 5-6weeks sub-group and 7-9 weeks sub-group. Threatened abortion was diagnosed with vaginal bleeding or abdominal pain occurrences and treated with oral dydrogesterone $20 \mathrm{mg}$ twice a day. Eighteen cases in miscarriage group and 12 cases in normal group were diagnosed with threatened abortion at 5-6 weeks. Their blood was taken for measurement of progesterone and then they were treated with dydrogesterone (Fig. 1 and Table 2). At 7-9 weeks, totally 65 cases were diagnosed with threatened abortion in normal group and 71 cases in miscarriage group. The blood taken for measurement of progesterone was prior to or after starting dydrogesterone treatment at 7-9 weeks (Fig.1 and Table 3).

Transvaginal ultrasound scans were performed by the same experienced attending doctor. Normal pregnancy group was diagnosed by ultrasound screening (Ultrasonic apparatus GE V730) with fetus survival in accordance with 12 weeks of gestational age. Miscarriage was diagnosed with ultrasonic criteria [15]: 1) Crown-rump length of $\geq 7 \mathrm{~mm}$ and no heartbeat; 2) Mean sac diameter of $\geq 25 \mathrm{~mm}$ and no embryo; 3) Absence of embryo with heartbeat $\geq 2$ weeks after a scan that showed a gestational sac without a yolk sac; 4) Absence of embryo with heartbeat $\geq 11$ days after a scan that showed a gestational sac with a yolk sac. The number of patients who were performed ultrasound scans at different weeks is shown in Fig. 1.

\section{Estradiol, progesterone and $\beta$-HCG measurement}

Serum estradiol, progesterone and $\beta$-HCG levels were measured with chemiluminescence on Roche Elecsys 


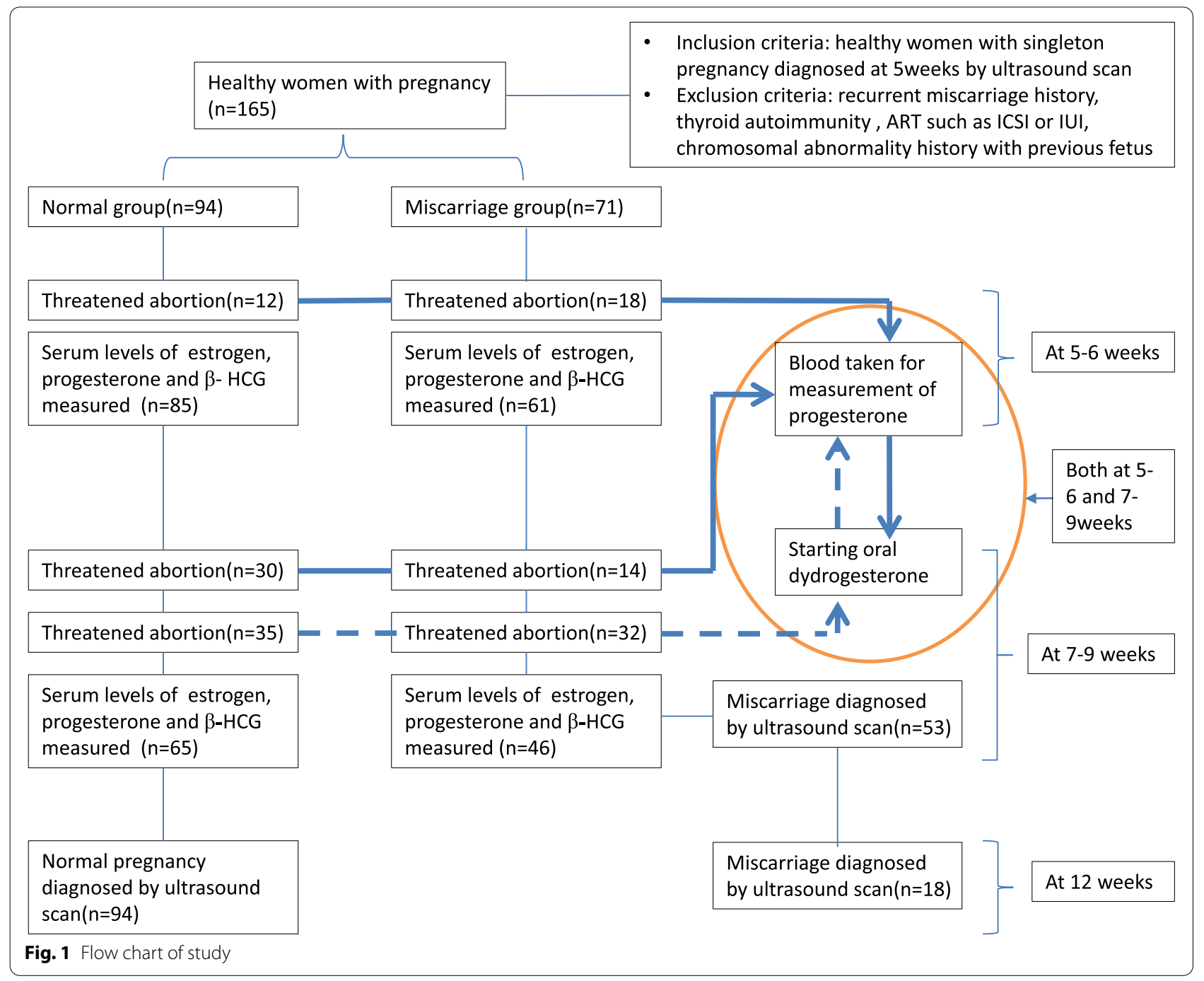

2010 type instrument. The variations were $6.4 \%$ between the batches and $6.0 \%$ within the batches.

\section{Statistical analysis}

The statistical analysis was performed using SPSS 16.0 software. A $P$-value of $\leq 0.05$ was considered statistically significant for all statistical tests. In order to obtain measurement data for single factor variance analysis, the comparison between groups was conducted by Tukey post hoc test. The Chi-square test was adopted to show the number of pregnancy and parity significance compared between two groups. The miscarriage outcome, as state variables, was calculated based on the area under ROC curve (AUC) of estradiol, progesterone and $\beta$-HCG levels, respectively. The Youden index was used to determine the optimal sensitivity and specificity; cutoff values to Youden index's biggest diagnosis were calculated, which were the degree of sensitivity, specific, and missed diagnosis to this point. Diagnosis agreements between estradiol, progesterone, $\beta$-HCG cutoff levels and ultrasound were obtained with using the kappa coefficient ( $\mathrm{k}$ ). Univariate and multivariate logistic regressions were also used for the further measurements.

\section{Results}

Levels of serum estradiol, progesterone and $\beta$ - HCG

Characteristics of the two groups are presented in Table 1. The two groups were similar in women's age, number of pregnancies and the parity. Only three women with miscarriage were willing to detect chromosomal karyotype of the embryos. The results were normal. Table 2 presents the progesterone levels before starting oral dydrogesterone treatment in 
Table 1 The women's age, number of pregnancy and parity in two groups

\begin{tabular}{|c|c|c|c|c|c|c|c|}
\hline \multirow[t]{2}{*}{ Groups } & \multirow[t]{2}{*}{ Number of cases } & \multirow[t]{2}{*}{ Age (years old) } & \multicolumn{3}{|c|}{ Cases with number of pregnancy } & \multicolumn{2}{|c|}{ Cases with parity } \\
\hline & & & 1 & 2 & 3 & 0 & 1 \\
\hline Normal pregnancy & 94 & $34.7 \pm 6.7$ & 52 & 37 & 5 & 90 & \\
\hline Miscarriage & 71 & $32.5 \pm 8.9$ & 41 & 23 & 7 & 69 & 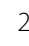 \\
\hline$P$ & & $0.07 \#$ & 0.44 & & & 0.4 & \\
\hline
\end{tabular}

\# No significantly different between miscarriage and normal pregnancy

a Chi-Square test

Table 2 Progesterone levels before starting oral dydrogesterone treatment in women with or without threatened abortion at 5-6 weeks of gestation in normal and miscarriage groups

\begin{tabular}{lll}
\hline Groups (number of cases) & $\begin{array}{l}\text { Progesterone levels }(\mathbf{n g} / \mathbf{m l}) \text { before } \\
\text { starting oral dydrogesterone treatment in } \\
\text { women with threatened abortion (number } \\
\text { of cases) }\end{array}$ & $\begin{array}{l}\text { Progesterone levels }(\mathbf{n g} / \mathbf{m l}) \text { in women } \\
\text { without threatened abortion and oral } \\
\text { dydrogesterone treatment (number of } \\
\text { cases) }\end{array}$ \\
\hline Normal pregnancy $(n=85)$ & $22.56 \pm 7.40(n=12)$ & $25.62 \pm 5.80(n=73)$ \\
Miscarriage $(n=61)$ & $23.26 \pm 8.23(n=18)$ & $22.17 \pm 5.60(n=43)$ \\
\hline
\end{tabular}

\# No significantly different between women with and without threatened abortion in miscarriage and normal pregnancy

women with or no threatened abortion at 5-6 weeks of gestation in normal pregnancy and miscarriage groups. Progesterone levels were slightly higher in normal pregnancies without giving dydrogesterone than with preparing to take oral dydrogesterone (Table 2). Table 3 presents the blood taken for measurement of progesterone before or after starting dydrogesterone treatment at 7-9 weeks of gestation in threatened abortion women of two groups. It showed higher levels of progesterone with giving dydrogesterone than without starting oral dydrogesterone in two groups. But the progesterone levels were not significantly different between without oral dydrogesterone and with oral dydrogesterone in two groups (Tables 2 and 3).

The mean maternal age in miscarriage was not significantly $(P>0.05)$ different from those in the normal pregnancy group at $5-6$ weeks or 7-9 weeks of gestation (Tables 4 and 5).

At the 5-6weeks and 7-9 weeks of gestation, serum estradiol levels were lower in miscarriage group as compared with those in normal pregnancy group $(P<0$. 05) (Table 4 and 5). Similarly, patients with miscarriage showed lower progesterone levels at 7 - 9weeks of gestation $(P<0.05)$ (Table 5). In contrast, no statical differences were observed between miscarriage and normal pregnancy groups in serum progesterone concentration at 5-6weeks of gestation and $\beta$-HCG levels at 5-6weeks and 7-9 weeks of gestation, though the levels were higher in normal groups $(P>0.05)$ (Table 4 and 5).
Normal pregnancy group had significantly elevated serum levels of estradiol, progesterone and $\beta$-HCG at 7-9 gestational weeks as compared with those at 5-6 gestational weeks $(P<0.05)$ (Table 6).

\section{Serum estradiol, progesterone and $\beta$-HCG levels of ROC curve analysis}

At 7-9weeks, AUC of serum estradiol was 0.866, with 95\% confidence interval (CI) (0.793 0.938) ( $P=0.000$, Fig. 2). At the optimal threshold according to Youden index up to 0.633 for cutoff value of $576 \mathrm{pg} / \mathrm{ml}$, the sensitivity, the specificity and the missed diagnosis degrees were $0.804,0.829$, and 0.171 , respectively (Fig. 2). The AUC for progesterone at $7-9$ weeks was 0.766 , with $95 \% \mathrm{CI}(0.672 \sim 0.861)(P<0.001$, Fig. 3), and for estradiol at the $5-6$ weeks decreased to 0.709 , with $95 \% \mathrm{CI}(0.616 \sim 0.801)(P=0.000$, Fig. 2).

Cutoff value of serum estradiol at 5-6weeks according to the Youden index of 0.374 was $320 \mathrm{pg} / \mathrm{ml}$, with the sensitivity of 0.800 , specificity of 0.574 and missed diagnosis degree of 0.426 , respectively (Fig. 2). At 7-9 weeks, cutoff value of progesterone was $15.27 \mathrm{ng} / \mathrm{ml}$ to the Youden index of 0.479 , with the sensitivity of 0.921 , the specificity of 0.558 , and the missed diagnosis of 0.442 , respectively (Fig. 3).

The levels of concordance on diagnosing miscarriage between the estradiol at 7-9weeks, the estradiol at 5-6weeks, progesterone at 7-9weeks cutoff measurements and ultrasound was moderate $(\kappa=0.425,0.419$ and $0.599, P=0.000$, respectively).

However, at 5-6weeks, AUC of serum progesterone of 0.529 showed no statistical significance $(P=0.572)$ 
Table 3 Progesterone levels after or before starting oral dydrogesterone treatment at 7-9 weeks of gestation in women with threatened abortion in normal and miscarriage groups

\begin{tabular}{llll}
\hline $\begin{array}{l}\text { Women with threatened abortion and } \\
\text { treated with oral dydrogesterone in two } \\
\text { groups (number of cases) }\end{array}$ & $\begin{array}{l}\text { Progesterone levels }(\mathbf{n g} / \mathbf{m l}) \text { after oral } \\
\text { dydrogesterone treatment (number of } \\
\text { cases) }\end{array}$ & $\begin{array}{l}\text { Progesterone levels }(\mathbf{n g} / \mathbf{m l}) \text { before } \\
\text { starting oral dydrogesterone } \\
\text { treatment(number of cases) }\end{array}$ \\
\hline Normal pregnancy $(n=65)$ & $26.12 \pm 7.18(n=35)$ & $23.57 \pm 7.20(n=30)$ \\
Miscarriage $(n=46)$ & $20.12 \pm 6.31(n=32)$ & $17.18 \pm 6.18(n=14)$ & $0.159 \#$ \\
\hline
\end{tabular}

\# No significantly different between after and before starting oral dydrogesterone treatment in miscarriage and normal pregnancy

Table 4 Age, serum levels of estradiol, progesterone and $\beta-H C G$ in normal pregnancy and miscarriage groups at 5-6weeks of gestation by Tukey post hoc test

\begin{tabular}{|c|c|c|c|c|c|}
\hline Group & The number of cases & Age (years old) & $\begin{array}{l}\text { Estradiol } \\
(\mathrm{pg} / \mathrm{ml})\end{array}$ & $\begin{array}{l}\text { Progesterone } \\
(\mathrm{ng} / \mathrm{ml})\end{array}$ & $\begin{array}{l}\beta \text {-HCG } \\
(\mathrm{mlU} / \mathrm{ml})\end{array}$ \\
\hline Normal pregnancy & 85 & $31.5 \pm 6.8$ & $559 \pm 356$ & $22.69 \pm 7.87$ & 5295.98a \\
\hline Miscarriage & 61 & $32.3 \pm 3.7$ & $375 \pm 233$ & $22.07 \pm 9.58$ & $2926.25 a$ \\
\hline$P$ & & $0.132 \#$ & $0.001^{* *}$ & $0.684 \#$ & $0.063 \#$ \\
\hline
\end{tabular}

**Significantly lower in miscarriage than that in normal pregnancy $(P<0.01)$

\# No significantly different between miscarriage and normal pregnancy

a For the geometric mean

to predict miscarriage in first trimester. Likewise, at $5-6$ weeks and at 7-9weeks, AUCs of serum $\beta$-HCG were 0.396 and 0.661 with no statistical significance $(P=0.059, P=0.059$ respectively).

\section{Multi-marker ROC analysis}

A multivariate logistic regression was performed to evaluate its ability to predict miscarriage based on all 3 biomarkers plus gestational age. At the optimal cutoffs for each marker and all logistic and AUC data were described in Table 7. The performance of the dual markers of estradiol and progesterone analysis $(\mathrm{AUC}=0.871$, CI 0.793-0.950) was slightly better than the single marker at 7-9 weeks. So was multi- marker analysis (AUC $=0.869$, CI 0.759-0.980). $\beta$ - HCG by itself did not have a predictive AUC of 0.661 at 7-9weeks, nor did it increase the potency of estradiol or estradiol combined with progesterone, although its combination of progesterone had greater AUC of 0.865 than 0.766 of progesterone alone. Similarly, the diagnosis probability of miscarriage was the highest $92.9 \%$ using markers of estradiol combination with progesterone or with progesterone and $\beta-$ HCG at 7-9 weeks.

AUC of $\beta$-HCG at 0.396 or progesterone at 0.529 at 5-6 weeks showed no predictive effect itself; however, $\beta$-HCG or progesterone provide additional utility of estradiol prediction at 5-6weeks, with AUC $0.770(0.672-0.869)$ for $\beta$-HCG and estradiol, AUC 0.768 (CI 0.670-0.866) for $\beta$-HCG, estradiol and progesterone, and AUC 0.739 (CI 0.651-0.827) for estradiol and progesterone (see Table 7). Of course, all of these predictions at 5-6weeks are less effective than the dual or multi markers predictions at $7-9$ weeks.

\section{Discussion}

Our study showed that the serum estradiol, progesterone and HCG levels increased with gestational age during 5-9 weeks, which was consistent with previous results $[2,16]$. In the miscarriage group, estradiol and progesterone were significantly decreased. Previous studies also showed that the levels of these indicators were decreased, indicating a poor pregnancy outcome [2, 17]. However, the value of these indicators in predicting miscarriage is still unclear.

Our results showed that the serum markers within 9 weeks of gestation can be used to differentiate the possibilities of normal pregnancy and miscarriage in first trimester. Specifically, low serum estradiol levels at 5-6 and 7-9 weeks and progesterone at 7-9weeks can serve as the predictors, while $\beta$-HCG levels showed no prediction effect.

Our further dual or multi markers analysis showed that the AUC of estradiol combined with progesterone could reach the largest 0.871 , and estradiol alone was 0.866 . $\beta$-HCG did not increase the predictive efficacy of estradiol combined with progesterone or estradiol at 7-9 weeks for miscarriage. The reason could be that the predictive effect of estradiol was too great to be affected by $\beta$-HCG. The predictive effect of dual or multi markers at $5-6$ weeks was lower than that at $7-9$ weeks. $\beta$-HCG or 
Table 5 Age, serum levels of estradiol, progesterone and $\beta$-HCG in normal pregnancy and miscarriage groups at 7 to 9 weeks of gestation by Tukey post hoc test

\begin{tabular}{lllllc}
\hline Group & The number of cases & Age (years old) & $\begin{array}{l}\text { Estradiol } \\
\text { (pg/ml) }\end{array}$ & & $\begin{array}{l}\text { Progesterone } \\
(\mathbf{n g} / \mathbf{m l})\end{array}$ \\
\hline Normal pregnancy & 65 & $34.1 \pm 6.2$ & $1209 \pm 785$ & $25.84 \pm 8.61$ & $\begin{array}{l}\boldsymbol{\beta} \text {-HCG } \\
(\mathbf{m l U} / \mathbf{m l})\end{array}$ \\
Miscarriage & 46 & $32.2 \pm 3.7$ & $39 \pm 289$ & $17.15 \pm 8.62$ & $32549 \mathrm{a}$ \\
$P$ & & $0.342 \#$ & $0.000^{* *}$ & $0.000^{* *}$ & $17700 \mathrm{a}$ \\
\hline
\end{tabular}

**Significantly lower in miscarriage than that in normal pregnancy $(P<0.01)$;

\# No significantly different between miscarriage and normal pregnancy;

a For the geometric mean

Table 6 Serum levels of estradiol, progesterone and $\beta-H C G$ at different gestational ages in normal pregnancy groups

\begin{tabular}{lllll}
\hline Gestational age & Number of cases & $\begin{array}{l}\text { Estradiol } \\
(\mathbf{p g} / \mathbf{m l})\end{array}$ & $\begin{array}{l}\text { Progesterone } \\
(\mathbf{n g} / \mathbf{m l})\end{array}$ & $\begin{array}{l}\boldsymbol{\beta}-\mathrm{HCG} \\
(\mathbf{m l U} / \mathbf{m l})\end{array}$ \\
\hline $5-6$ weeks & & $559 \pm 356$ & $22.69 \pm 7.87$ & $5295.98 \mathrm{a}$ \\
$7-9$ weeks & 85 & $1209 \pm 785$ & $25.84 \pm 8.61$ & $32549 \mathrm{a}$ \\
$P$ & 65 & $0.000^{* *}$ & $0.025^{*}$ & $0.000^{* *}$ \\
\hline
\end{tabular}

,**Significantly $\left({ }^{*} P<0.05,{ }^{* *} P<0.01\right)$ higher at 7-9 gestational weeks than that at 5-6 weeks in normal pregnancy women;

a For the geometric mean

progesterone level alone had no predictive significance, but their combination with estradiol could improve the predictive effect of estradiol at 5-6weeks. Especially, dual of $\beta$-HCG and estradiol could perform better. So lower levels of estradiol are the primary predictor of miscarriage at 5 to 9 weeks. Our results are consistent with Yang $\mathrm{Li}$, etc's report [2]. The difference is that our study objective was to predict miscarriage within 12 weeks, while Yang Li, etc's was to exclude other adverse outcomes of normal pregnancy, such as biochemical ectopic pregnancy and miscarriage.

Progesterone can provide endocrine support. Renzo, etc. [18] reported high progesterone level has a calming effect, reducing the uterine contraction intensity and frequency, and thereby extends endometrial secretion period and coordination and embryonic development in planting window synchronization. It was found that progesterone can also improve the immune status by promoting the maternal-fetal interface CD56 + lymphocytes induced secretion of progesterone induced blocking factor (PIBF) to prevent immune rejection. Progesterone levels may help diagnose embryonic development. Puget etc. [19] reported that serum progesterone level lower than $6.2 \mathrm{ng} / \mathrm{ml}$ indicated lower prompt embryonic vitality. The sensitivity, specificity to diagnose an early pregnancy loss were $20 \%$ and $100 \%$.

In our study, we found that serum progesterone levels increased at 7-9 weeks of gestation in normal pregnancy compared to those at 5-6 weeks of gestation. Progesterone levels at 5-6weeks could not predict miscarriage in first trimester. But at 7-9weeks, progesterone levels can be a marker to predict miscarriage despite no more effective than serum estradiol levels at 7-9 weeks. More excitedly, it provides estradiol additional higher utility of prediction with the largest AUC of 0.871 .

Our result showed that progesterone could be a predictor at 7-9 weeks because the onset of substantial progesterone production is the 7th gestational week [16]. Similar in other studies, high progesterone level on the day of embryo transfer was a predictor of a higher ongoing pregnancy rate [20]. In $\mathrm{Ku} \mathrm{CW}$ et al's report [5], serum progesterone concentration increased linearly with gestational age from 5 to 13 weeks in women with normal pregnancies, and women with spontaneous miscarriage showed a marginal and non-significant increase in serum progesterone. Our results also showed higher progesterone levels at 7-9 gestational weeks than 5-6 gestational weeks in normal pregnancy. Similarly, women with miscarriage showed lower progesterone levels than normal pregnancy at 7-9weeks of gestation. The studies suggest the essential role of progesterone in supporting an early pregnancy.

Progesterone levels at 7-9weeks lower than cutoff value of $15.27 \mathrm{ng} / \mathrm{ml}$ could predict miscarriage in our study. That is accordance with Lek SM et al's study [6]. They also presented that the cut-off value for serum progesterone $(35 \mathrm{nmol} / \mathrm{L})$ demonstrated clinical relevance and allow clinicians to stratify patients into high and low risk groups for spontaneous miscarriage. The higher 

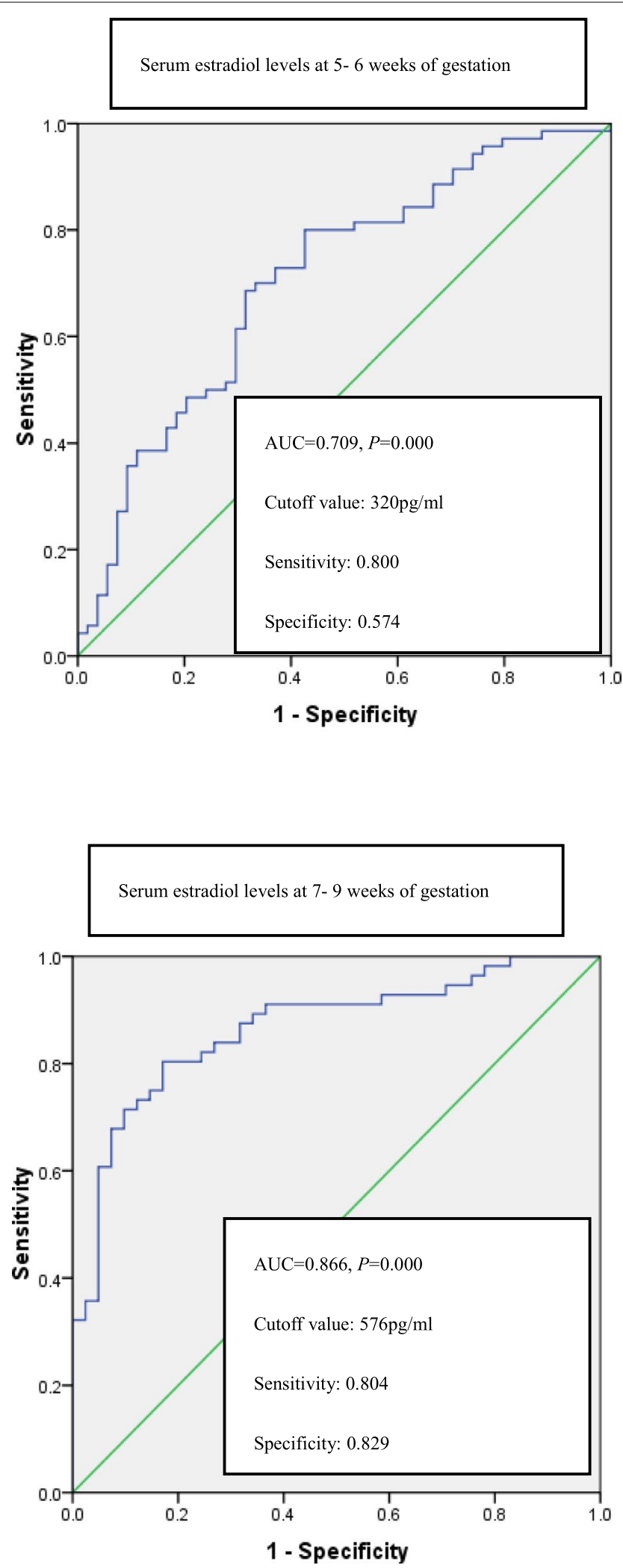

Fig. 2 Estradiol receiver- operating characteristic (ROC) curves at 5-6 weeks and 7-9 weeks of gestation. The cutoff value, the sensitivity and specificity degrees were also shown 


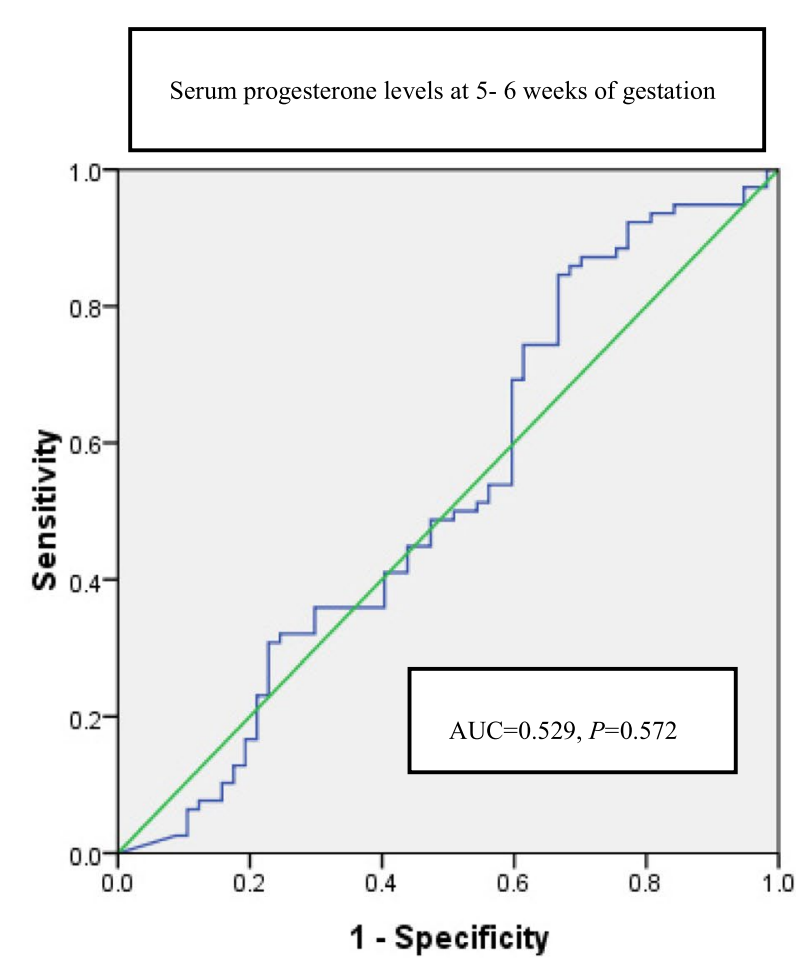

Serum progesterone levels at 7- 9 weeks of gestation

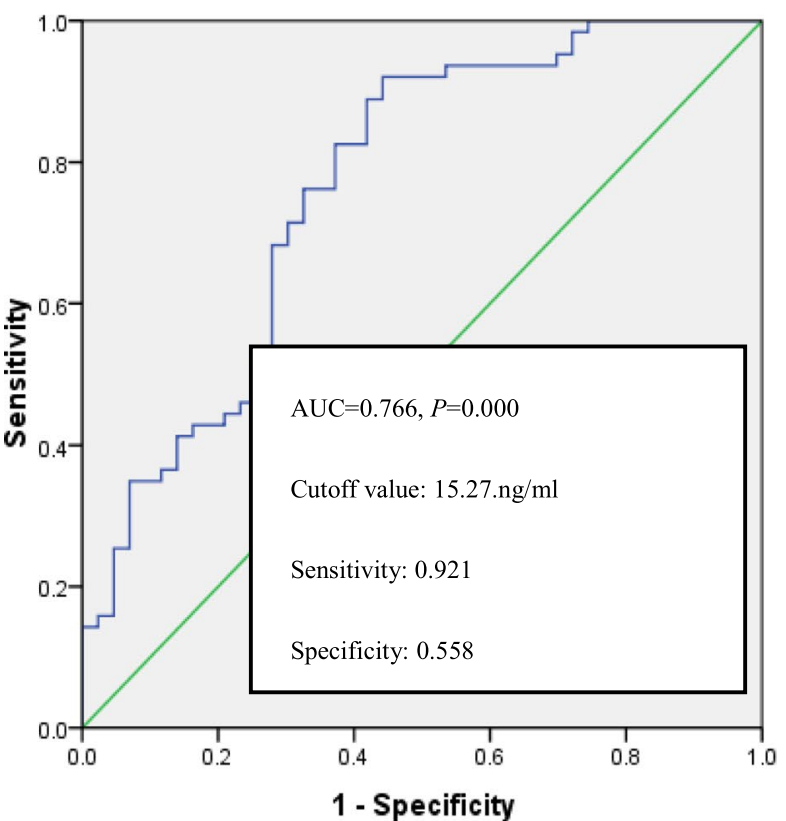

Fig. 3 Progesterone receiver- operating characteristic (ROC) curves at 5-6 weeks and 7-9 weeks of gestation. The cutoff, the sensitivity and specificity degrees were also shown 
Table 7 The probabilities and area of ROC of multi-markers, dual of estradiol and progesterone, estradiol and progesterone using logistic regression and $\mathrm{ROC}$ analyze

\begin{tabular}{|c|c|c|c|c|c|}
\hline Markers & $\begin{array}{l}\text { Probabilities of } \\
\text { miscarriage }\end{array}$ & $P$ & Area of ROC & $P$ & Cutoff value \\
\hline $\begin{array}{l}E 2+P+\beta-H C G(7-9 \\
\text { weeks) }\end{array}$ & 92.9 & $0.001^{* *}$ & $0.869(0.759-0.980)$ & $0.000^{* *}$ & \\
\hline E2+P (7-9 weeks) & 73.8 & $0.000^{* *}$ & $0.871(0.793-0.950)$ & $0.000^{* *}$ & \\
\hline $\mathrm{E} 2+\beta$-HCG (7-9weeks) & 92.9 & $0.005^{* *}$ & $0.795(0.641-0.948)$ & $0.000^{* *}$ & \\
\hline$P+\beta-H C G(7-9$ weeks) & 82.1 & $0.000^{* *}$ & $0.865(0.760-0.968)$ & $0.000^{* *}$ & \\
\hline E2 (7-9 weeks) & 85.7 & $0.000^{* *}$ & $0.866(0.793-0.938)$ & $0.000^{* *}$ & $576 \mathrm{pg} / \mathrm{ml}$ \\
\hline P (7-9 weeks) & 68.2 & $0.000^{* *}$ & $0.766(0.672-0.861)$ & $0.000^{* *}$ & $15.27 \mathrm{ng} / \mathrm{ml}$ \\
\hline$\beta$-HCG(7-9weeks) & - & $0.087 \#$ & 0.661 & 0.059\# & 3098.765IU/L \\
\hline $\mathrm{E} 2+\mathrm{P}+\beta-\mathrm{HCG}(5-6$ weeks) & 80.4 & $0.000^{* *}$ & $0.768(0.670-0.866)$ & $0.000^{* *}$ & \\
\hline$E 2+P(5-6$ weeks $)$ & 80.4 & $0.012^{* *}$ & 0.739(0.651-0.827) & $0.000^{* *}$ & \\
\hline E2+ $\beta-H C G(5-6 w e e k s)$ & 86.3 & $0.000^{* *}$ & $0.770(0.672-0.869)$ & $0.000^{* *}$ & \\
\hline$P+\beta-H C G(5-6$ weeks) & 73.6 & $0.03^{*}$ & $0.667(0.561-0.772)$ & $0.004^{* *}$ & \\
\hline E2 (5-6 weeks) & 72.7 & $0.000^{* *}$ & $0.709(0.616-0.801)$ & $0.000^{* *}$ & $320 \mathrm{pg} / \mathrm{ml}$ \\
\hline P (5-6 weeks) & 28.1 & $0.046 \#$ & 0.529 & $0.572 \#$ & $8.47 \mathrm{ng} / \mathrm{ml}$ \\
\hline$\beta$-HCG (5-6 weeks) & - & 1.050\# & 0.396 & 0.059\# & 2858.6IU/L \\
\hline
\end{tabular}

$*{ }^{* *}$ Significantly prediction utility for miscarriage $\left({ }^{*} P<0.05,{ }^{* *} P<0.01\right)$

\# No significantly prediction utility for miscarriage

$E 2$ estradiol, $P$ progesterone, $E 2+P+\beta-H C G$ multi markers analysis

cutoff value of progesterone in our study may be because the inspection interval was 7-9 weeks to predict miscarriage within 12 weeks of gestation, while in Lek SM's study was $6-10$ weeks to predict miscarriage prior to 16 weeks of gestation.

HCG is a glycoprotein secreted after fertilization of sterol cell in 6-8 weeks. It peaks at 8-12 weeks of gestation for $1-2$ weeks and then begins to reduce [21]. Low serum HCG during pregnancy is considered a natural miscarriage or a poor pregnancy $[2,4,21]$. Dynamic level of HCG may serve better because serum HCG is increased at the rate of $66 \%$ per $48 \mathrm{~h}$ in normal pregnancy. HCG increase rate less than $66 \%$ indicates adverse pregnancy outcomes [21,22].

Compared with those results, $\beta$-HCG was tested at $5-9$ weeks only twice in our study, which is not enough to predict the overall miscarriage outcome within 12 weeks. It may be because that pregnancy is an unstable and susceptible period [23]. However more interestingly, $\beta$-HCG combined with estradiol at 5-6weeks significantly improved the prediction. It may be related to the HCG plateaued in this period [22].

Our results were similar to other studies which found that low values and low growth rates of estradiol and $\beta$-HCG probably indicate bad pregnancy outcomes [2]. However, another report revealed a higher, not lower, level of $\beta$-HCG and estrogen during the first 6 weeks of pregnancy, suggesting a novel association between $\beta-$ HCG, estrogen, and threatened abortion [23, 24].
Unfortunately, this study was limited by its small sample size, unconvincing trial design, and inadequate exploration of the underlying mechanisms [23].

Early miscarriage is usually diagnosed with pelvic ultrasound after a woman experienced vaginal bleeding or abdominal pains [22]. If ultrasound at the 8.5 weeks pregnancy showed embryonic survival, 95\% of pregnancies within 14 weeks would not end up to miscarriage [25]. Findings were controversial although some studies on ultrasound scan, including subchorionic hemorrhage, fetal heart rate, crown-rump length and yolk sac diameter associated with pregnancy loss existed $[7,8]$. So, prediction markers before 8.5 weeks need to be further inspected. It was found in our study that estradiol at 5-9 weeks of gestation makes a key effect on prediction of miscarriage in first trimester.

Current findings differ from previous study [2], which showed the values of estradiol at every gestational week from 5 to 8 weeks to predict miscarriage. There are two reasons for the 5-6 weeks and 7-9 weeks groups used in our study.

First is related to the period of prenatal clinic examination. Generally, ultrasound scan may show the fetal sac at 5-6weeks of gestation. More women are willing to come to the hospital during this period for examination. The women and doctors would test serum estradiol, progesterone and $\beta$ - HCG to understand the pregnancy status. These markers were getting more commonly used in the ART pregnancy. The second period of time to the 
hospital for examination is 7-9 weeks when most of the fetal bud and fetal heart could be seen by ultrasound [8]. Moreover, $95 \%$ of pregnancies within 14 weeks would not end up to miscarriage if embryo survives before the first 9 weeks of pregnancy $[24,25]$. The second reason is the number of clinical patients in these two stages are relatively large and the data collection is relatively comprehensive. So, we collected the data at these two stages for this study.

Compared with previous study with higher AUC of estradiol in the 7th and 8th week, taking $590.5 \mathrm{pg} /$ $\mathrm{mL}$ in the 7 th week, and $614.5 \mathrm{pg} / \mathrm{mL}$ in the 8 th week as cutoff levels of to estradiol predict bad pregnancy outcome [2], current results also showed that levels of estradiol individually or combination with progesterone has the higher AUC at 7-9 weeks. Our results taking $576 \mathrm{pg} / \mathrm{ml}$ as cutoff value levels of estradiol were slightly lower than $590.5 \mathrm{pg} / \mathrm{mL}$ in the 7 th week, and $614.5 \mathrm{pg} / \mathrm{mL}$ in the 8th week in previous study. The difference may be our investigation interval was longer with 7-9 weeks. Current findings may help more women suffered miscarriage prior to 9 weeks than 8 weeks. Therefore, our study has certain rationality and advantages. Of course, our sample size is small, and larger samples and further prospective studies are needed to verify the results.

Supplementation with different progestogens in early pregnancy has been attempted to rescue a pregnancy in women with early pregnancy bleeding to treat threatened miscarriage [26]. Oral dydrogesterone are used to treat threatened abortion which was further stated effective in recent study [27]. In our study, oral dydrogesterone had no effect on serum progesterone levels, though higher levels of progesterone with giving dydrogesterone were shown than without starting oral dydrogesterone in two groups. It may be because dydrogestogen mainly alters maternal cytokine profiles to manage pregnancy complications [28]. Table 2 presented lower progesterone levels despite of no significance in women needed to be given oral dydrogesterone than without dydrogesterone. It may resulted from that women needed to be given oral dydrogesterone were diagnosed with threatened abortion in normal pregnancy group.

\section{Conclusions}

Although ultrasound and continuous blood HCG value can, to a certain extent, determine the risk of miscarriage, it is still needed to predict high-risk pregnancy before clinical symptoms with other biomarkers [10]. Estrogen and progesterone reflecting the final pregnancy outcomes have been recognized, but few literature have indicated the specific hormone testing time and levels for miscarriage significance. In this study, we found that the miscarriage in first trimester may be predicted by estradiol levels, and the threshold sensitivity of cutoff value at 7-9 weeks of gestation is higher. Our study had limited cases and more case and multicenter studies need to be further researched.

Conclusively, low serum levels such as dual of estradiol and progesterone or estradiol alone at 7-9 weeks of gestation can be used to better predict miscarriage in first trimester. $\beta$-HCG or progesterone combing estradiol at 5-6 weeks of gestation may serve as better predictors also.

\section{Abbreviations \\ $\beta$-HCG: $\beta$-human chorionic gonadotropin; ROC: Receiver operating charac- teristic; ART: Artificial assisted pregnancy technology; ICSI: Intracytoplasmic injection; IUI: Intrauterine insemination; AUC: Area under the ROC curve; PIBF: Progesterone induced blocking factor.}

\section{Acknowledgements}

The authors would like to thank Yang Liu supporting on the English editing, and to thank the staff collaborating on the study, particularly during data collection at the Clinic of Obstetrics and Gynecology, Beijing Hospital, National Center of Gerontology; Institute of Geriatric Medicine, Chinese Academy of Medical Sciences, Beijing, China.

\section{Authors' contributions}

Wenhui Deng, Rui Sun and Jun Du wrote the main manuscript test. Xue Wu, Lljie Ma, Min Wang and Qiubo Lv prepared figures and tables. All authors reviewed the manuscript. The author(s) read and approved the final manuscript.

\section{Funding}

This study was no funded.

\section{Availability of data and materials}

Available from the corresponding author (dengwenhui@hotmail.com) and will be deposited in a public repository as soon as we gain the permission to do so.

\section{Declarations}

Ethics approval and consent to participate

We confirm that all methods were carried out in accordance with relevant guidelines and regulations. An informed consent was exempted by Committee on Human Research (Institutional Review Board) of the Beijing Hospital, National Center of Gerontology; Institute of Geriatric Medicine, Chinese Academy of Medical Sciences. The study protocol was approved by Committee on Human Research (Institutional Review Board) of the Beijing Hospital, National Center of Gerontology; Institute of Geriatric Medicine, Chinese Academy of Medical Sciences (approval notice: No.2020BJYYEC-279-01).

\section{Consent for publication}

Not applicable.

\section{Competing interests}

I declare that the authors have no competing interests as defined by BMC, or other interests that might be perceived to influence the results and/or discussion reported in this paper.

\section{Author details}

${ }^{1}$ Department of Obstetrics and Gynecology, Beijing Hospital, National Center of Gerontology; Institute of Geriatric Medicine, Chinese Academy of Medical Sciences, Beijing 100730, P. R. China. ${ }^{2}$ Department of Obstetrics and Gynecology, Tongzhou Maternal and Child Health Hospital of Beijing, Beijing 101100, 
P. R. China. ${ }^{3}$ Department of Pathology, Beijing Hospital, National Center of Gerontology; Institute of Geriatric Medicine, Chinese Academy of Medical Sciences, Beijing 100730, P. R. China.

Received: 5 March 2021 Accepted: 23 September 2021 Published online: 10 February 2022

\section{References}

1. Practice Committee of the American Society for Reproductive Medicine. Evaluation and treatment of recurrent pregnancy loss: a committee opinion. Fertil Steril. 2012;98(5):1103-11. https://doi.org/10.1016/j. fertnstert.2012.06.048 Epub 2012 Jul 24. PMID: 22835448.

2. Li Y, Zhang J, Zhang K, Wang E, Shu J. Significance of dynamically monitoring serum estrogen and $\beta$-human chorionic gonadotropin in early pregnancy assessment. J Clin Lab Anal. 2021;35(1):e23559. https://doi. org/10.1002/jcla.23559. Epub 2020 Sep 6. PMID: 32892443; PMCID: PMC7843287.

3. Huang N, Chi H, Qiao J. Role of regulatory T cells in regulating fetalmaternal immune tolerance in healthy pregnancies and reproductive diseases. Front Immunol. 2020;11:1023. https://doi.org/10.3389/fimmu. 2020.01023. PMID: 32676072; PMCID: PMC7333773.

4. Bobdiwala S, Saso S, Verbakel JY, Al-Memar M, Van Calster B, Timmerman $D$, et al. Diagnostic protocols for the management of pregnancy of unknown location: a systematic review and meta-analysis. BJOG. 2019;126(2):190-8. https://doi.org/10.1111/1471-0528.15442 Epub 2018 Sep 20. PMID: 30129999.

5. Ku CW, Allen JC Jr, Lek SM, Chia ML, Tan NS, Tan TC. Serum progesterone distribution in normal pregnancies compared to pregnancies complicated by threatened miscarriage from 5 to 13 weeks gestation: a prospective cohort study. BMC Pregnancy Childbirth. 2018;18(1):360. https://doi.org/10.1186/s12884-018-2002-z PMID: 30185145; PMCID: PMC6126027.

6. Lek SM, Ku CW, Allen JC Jr, Malhotra R, Tan NS, Østbye T, et al. Validation of serum progesterone $<35 \mathrm{nmol} / \mathrm{L}$ as a predictor of miscarriage among women with threatened miscarriage. BMC Pregnancy Childbirth. 2017;17(1):78. https://doi.org/10.1186/s12884-017-1261-4 PMID: 28264669; PMCID: PMC5340043.

7. Detti L, Francillon L, Christiansen ME, Peregrin-Alvarez I, Goeske PJ, Bursac Z, Roman RA. Early pregnancy ultrasound measurements and prediction of first trimester pregnancy loss: A logistic model. Sci Rep. 2020;10(1):1545. https://doi.org/10.1038/s41598-020-58114-3. PMID: 32005925; PMCID: PMC6994659.

8. DeVilbiss EA, Mumford SL, Sjaarda LA, Connell MT, Plowden TC, Andriessen VC, et al. Prediction of pregnancy loss by early first trimester ultrasound characteristics. Am J Obstet Gynecol. 2020;223(2):242. e1-242.e22. https://doi.org/10.1016/j.ajog.2020.02.025 Epub 2020 Feb 25. PMID: $32109464 ;$ PMCID: PMC7994016.

9. Pillai RN, Konje JC, Tincello DG, Potdar N. Role of serum biomarkers in the prediction of outcome in women with threatened miscarriage: a systematic review and diagnostic accuracy meta-analysis. Hum Reprod Update. 2016;22(2):228-39. https://doi.org/10.1093/humupd/dmv054 Epub 2015 Dec 9. PMID: 26663220.

10. Andersen LB, Dechend R, Karumanchi SA, Nielen J, Joergensen JS, Jensen TK, et al. Early pregnancy angiogenic markers and spontaneous abortion: an Odense Child Cohort study. Am J Obstet Gynecol. 2016;215(5):594.e1-594.e11. https://doi.org/10.1016/j.ajog.2016.06.007.

11. Zhang W, Tian Y, Xie D, Miao Y, Liu J, Wang X. The impact of peak estradiol during controlled ovarian stimulation on the cumulative live birth rate of IVF/ICSI in non-PCOS patients. J Assist Reprod Genet. 2019;36(11):2333-2344. https://doi.org/10.1007/s10815-019-01568-w. Epub 2019 Sep 4. PMID: $31485870 ;$ PMCID: PMC6885456.

12. Verma P, Verma R, Nair RR, Budhwar S, Khanna A, Agrawal NR, Sinha $R$, Birendra R, Rajender S, Singh K. Altered crosstalk of estradiol and progesterone with Myeloid-derived suppressor cells and Th1/Th2 cytokines in early miscarriage is associated with early breakdown of maternal-fetal tolerance. Am J Reprod Immunol. 2019;81(2):e13081. https://doi.org/10.1111/aji.13081. Epub 2019 Jan 28. PMID: 30589483.11-30589483.12
13. Gao Q, Wang M, Rong T. Serum estradiol level in pregnant women of four to eight weeks and its relationship with threatened abortion. Journal of Shandong University (Health Science). 2008;46(9):884-6 http:// yxbwk.njournal.sdu.edu.cn/CN/Y2008/V46/19/884.

14. Salazar EL, Calzada L. The role of progesterone in endometrial estradiol-and progesterone-receptor synthesis in women with menstrual disorders and habitual abortion. Gynecol Endocrinol. 2007;23(4):222-5. https://doi.org/10.1080/09513590701254030.

15. Doubilet PM, Benson CB, Bourne T, Blaivas M. Diagnostic criteria for nonviable pregnancy early in the first trimester. N Engl J Med. 2013;369(15):1443-51. https://doi.org/10.1056/nejmra1302417.

16. Neumann K, Depenbusch M, Schultze-Mosgau A, Griesinger G. Characterization of early pregnancy placental progesterone production by use of dydrogesterone in programmed frozen-thawed embryo transfer cycles. Reprod BioMed Online. 2020;40(5):743-51. https://doi.org/10. 1016/j.rbmo.2020.01.019 Epub 2020 Jan 31.

17. Jia Yun S Siew, John C Allen, Celene Y Y Hui, Chee Wai Ku, Rahul Malhotra, Truls Østbye, Thiam Chye Tan. The randomised controlled trial of micronised progesterone and dydrogesterone (TRoMaD) for threatened miscarriage. Eur J Obstet Gynecol Reprod Biol. 2018; 228: 319-324. https://doi.org/10.1016/j.ejogrb.2018.07.028. PMID: 30077119Epub $2018 \mathrm{Jul} 25$.

18. Di Renzo GC, Giardina I, Clerici G, Brillo E, Gerli S. Progesterone in normal and pathological pregnancy. Horm Mol Biol Clin Investig. 2016;27(1):35-48. https://doi.org/10.1515/hmbci-2016-0038. PMID: 27662646.

19. Puget C, Joueidi Y, Bauville E, Laviolle B, Bendavid C, Lavoué V, Le Lous M. Serial hCG and progesterone levels to predict early pregnancy outcomes in pregnancies of uncertain viability: A prospective study. Eur J Obstet Gynecol Reprod Biol. 2018;220:100-5. https://doi.org/10.1016/j. ejogrb.2017.11.020. Epub 2017 Dec 1. PMID: 29202392.

20. Boynukalin FK, Gultomruk M, Turgut E, Demir B, Findikli N, Serdarogullari $\mathrm{M}$, Coban $\mathrm{O}$, Yarkiner Z, Bahceci M. Measuring the serum progesterone level on the day of transfer can be an additional tool to maximize ongoing pregnancies in single euploid frozen blastocyst transfers. Reprod Biol Endocrinol. 2019;17(1):102. https://doi.org/10. 1186/s12958-019-0549-9. PMCID: PMC6884867, PMID: 31783865

21. Feng Youji, Shen Keng, Ma Ding. Obstetrics and Gynecology. Beijing people's health press (the third edition): 2015; 120-123.

22. Hardy P, Beeson L, Coomarasamy A. What is the best method for managing early miscarriage? BMJ. 2020; 368: 16438. https://doi.org/10.1136/ bmj.16438 (Published 20 January 2020).

23. Zhou J, Huang Z, Pan X, Leung WT, Li C, Chen L, et al. New thoughts in exploring the pathogenesis, diagnosis, and treatment of threatened abortion. BioScience Trends. 2019;13(3):284-5. https://doi.org/10.5582/ bst.2019.01155.

24. Xu L, Wei Q, Wu Q, Zhong Y, Li Y, Xu J, Zhu Y. Higher. $\beta$-human chorionic gonadotropin and estrogen levels during the first 6 weeks of pregnancy are associated with threatened abortion. Biosci Trends. 2019. https://doi.org/10.5582/bst.2019.01111.

25. Porter TF, Scott JR. Evidence-based care of recurrent miscarriage. Best Pract Res Clin Obstet Gynaecol. 2005;19(1):85-101. https://doi.org/10. 1016/j.bpobgyn.2004.11.005. PMID: 15749068.

26. Devall AJ, Papadopoulou A, Podesek M, Haas DM, Price MJ, Coomarasamy $A$, et al. Progestogens for preventing miscarriage: a network meta-analysis. Cochrane Database Syst Rev. 2021;4:CD013792. https:// doi.org/10.1002/14651858.CD013792.pub2.

27. Li L, Zhang Y, Tan H, Bai Y, Fang F, Faramand A, et al. Effect of progestogen for women with threatened miscarriage: a systematic review and meta-analysis. BJOG. 2020;127(9):1055-63. https://doi.org/10.1111/ 1471-0528.16261.

28. Ghadeer AbdulHussain, Fawaz Azizieh, Ma'asoumah Makhseed, Raj Raghupathy. Effects of progesterone, dydrogesterone and estrogen on the production of Th1/Th2/Th17 cytokines by lymphocytes from women with recurrent spontaneous miscarriage. J Reprod Immunol. 2020;140:103132. https://doi.org/10.1016/j.jri.2020.103132.

\section{Publisher's Note}

Springer Nature remains neutral with regard to jurisdictional claims in published maps and institutional affiliations. 